\title{
Impact of solvent polarity on the ligand configuration in tetravalent thorium $\mathrm{N}$-donor complexes
}

\author{
Thomas Sittel, ${ }^{*, a, b}$ Michael Trumm, ${ }^{b}$ Christian Adam, ${ }^{b}$ Andreas Geist, ${ }^{b}$ Petra J. Panak ${ }^{\mathrm{a}, \mathrm{b}}$ \\ a. Ruprecht-Karls-Universität Heidelberg, Institut für Physikalische Chemie, Im Neuenheimer \\ Feld 253, 69120 Heidelberg, Germany
}

b. Karlsruhe Institute of Technology (KIT), Institute for Nuclear Waste Disposal (INE), P.O. Box 3640, 76021 Karlsruhe, Germany

\begin{abstract}
A combined NMR spectroscopic and theoretical study on the complexation of diamagnetic Th(IV) with 2,6-bis(5,6-dipropyl-1,2,4-triazin-3-yl)pyridine (nPr-BTP) was performed. Different ligand configurations were observed for $\left[\mathrm{Th}(\mathrm{nPr}-\mathrm{BTP})_{3}\right]^{4+}$ complexes depending on the solvent's ability to actively form hydrogen bonds. In polar aprotic solvents, a complex is observed which is isostructural with $\left[\mathrm{M}(\mathrm{nPr}-\mathrm{BTP})_{3}\right]^{3+}(\mathrm{M}=\mathrm{Am}, \mathrm{Ln})$ complexes studied earlier. In contrast, ${ }^{1} \mathrm{H},{ }^{13} \mathrm{C}$ and ${ }^{15} \mathrm{~N}-\mathrm{NMR}$ spectra recorded in polar protic solvents showed twice as many signals, indicating a breakdown of symmetry. Supported by DFT calculations, this difference is explained by a solvent effect on the steric arrangement of the propyl moieties located on the triazine rings. Important information on bonding properties were obtained by ${ }^{15} \mathrm{~N}-\mathrm{NMR}$. In contrast to the respective Am(III) complex showing a significant covalent contribution, the Th(IV)-BTP interaction is mainly electrostatic.
\end{abstract}

\section{Introduction}

Heterocyclic N-donor ligands such as bis(triazinyl)pyridines (BTPs) or Bis(triazinyl)bipyridines (BTBPs) and similar ligands extract trivalent actinide ions An(III) selectively over lanthanide ions, Ln(III). The coordination chemistry of BTP and BTBP with An(III) and $\operatorname{Ln}(\mathrm{III})$ in solution has been studied in detail. ${ }^{1-}$

${ }^{3}$ Extending these studies to tetravalent actinides, Th(IV)-BTP complexes were prepared and studied by NMR.

NMR spectroscopy is a valuable tool to investigate the interaction between metal ions and donor ligands. For actinides and lanthanides, the interaction is mainly electrostatic. However, due to the overlap of frontier orbitals, the interaction is also partially covalent, resulting in a change of electron density distribution on the ligand. This corresponds directly to the change of the local magnetic field and is therefore correlated to the chemical shift.

NMR studies with actinide complexes are scarce, mainly because handling alpha emitters requires an elaborate infrastructure combined with strict safety precautions. Furthermore, the availability of these radionuclides is limited. Therefore, NMR studies mainly have been focused on the stoichiometry of $\mathrm{Ln}(\mathrm{III})-\mathrm{BT}(\mathrm{B}) \mathrm{P}$ complexes..$^{4-8}$ The $\mathrm{An}(\mathrm{III}) / \mathrm{Ln}$ (III) selectivity of BTP was demonstrated by ${ }^{1} \mathrm{H}$ NMR competition experiments using $\mathrm{U}(\mathrm{III})$ and $\mathrm{Ce}(\mathrm{III}) .{ }^{9}$ Comparative ${ }^{15} \mathrm{~N}$ NMR studies were performed to probe differences between Am(III)-N and $\operatorname{Ln}$ (III)-N bonds. ${ }^{10-12}$ Indeed, an upfield shift of approximately $300 \mathrm{ppm}$ was observed for the bonding nitrogen atoms in the Am(III) complexes compared to the Ln(III) references or the free ligand. This was seen as clear evidence for an increased covalent contribution to the Am(III)-N bond compared to the Ln(III)-bond. Covalency has long been reasoned as the driving forces behind An(III)/Ln(III) selectivity in soft donor complexes. ${ }^{13}$

To probe the effect of the cation's nuclear charge on the bonding properties in actinide $\mathrm{N}$-donor complexes, we extended our studies to tetravalent actinides. Th(IV) complexes with 2,6-bis(5,6- 


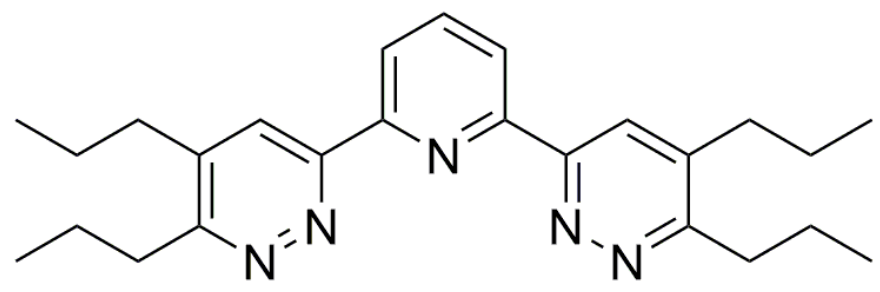

Figure 1 Structure of the nPr-BTP ligand.

dipropyl-1,2,4-triazin-3-yl)pyridine (nPr-BTP, cf. Figure 1) in a variety of solvents were fully characterized using ${ }^{1} \mathrm{H},{ }^{13} \mathrm{C},{ }^{15} \mathrm{~N}$ and ${ }^{19} \mathrm{~F}-\mathrm{NMR}$ spectroscopy. Quantum chemical studies on the density functional theory (DFT) level were performed to support the NMR results.

\section{Results and Discussion}

\section{Observations}

Figure 2 displays ${ }^{1} \mathrm{H}$ NMR spectra $(400.13 \mathrm{MHz}, 300 \mathrm{~K})$ of $\left[\mathrm{Th}(\mathrm{nPr}-\mathrm{BTP})_{3}\right](\mathrm{OTf})_{4}$ in tetrahydrofuran- $\mathrm{d}_{8}$ $\left(\right.$ THF- $\left.d_{8}\right)$ and methanol $d_{4}\left(\right.$ MeOD- $\left.d_{4}\right)$. The spectra differ from each other significantly. For THF $d_{8}$, one doublet at $9.09 \mathrm{ppm}\left(\mathrm{H}_{1} / \mathrm{H}_{3}\right)$ and one triplet at $8.69\left(\mathrm{H}_{2}\right)$ are observed with an integral ratio of 2:1. Further, two methyl groups are observed at $1.02 \mathrm{ppm}$ and $0.73 \mathrm{ppm}$. The spectrum matches the ${ }^{1} \mathrm{H}$ spectra of the respective $\left[\mathrm{M}(\mathrm{nPr}-\mathrm{BTP})_{3}\right]^{3+}(\mathrm{M}=\mathrm{Am}, \mathrm{Ln})$ complexes. ${ }^{11}$ Consequently, the $\mathrm{Th}(\mathrm{IV})$ complex is identified as $\left[\mathrm{Th}(\mathrm{nPr}-\mathrm{BTP})_{3}\right]^{4+}$. The $\mathrm{Th}^{4+}$ ion is coordinated by the nitrogen atoms in 2-position of the 1,2,4-triazinyl rings and by the pyridine nitrogen as seen as in Figure 2 on the right side.

For MeOD- $\mathrm{d}_{4}$, the spectrum shows two doublets at $9.21 \mathrm{ppm}\left(\mathrm{H}_{1}\right)$ and $9.15 \mathrm{ppm}\left(\mathrm{H}_{3}\right)$ as well as a triplet at $8.79 \mathrm{ppm}\left(\mathrm{H}_{2}\right)$ with an integral ratio of 1:1:1. Each methyl group is represented by its own signal. By analyzing the remaining aliphatic area with ${ }^{1} \mathrm{H}$-COSY correlation spectra, a double signal set is found for the $\mathrm{CH}_{2}$-groups. These findings indicate that the symmetry of the ligand is broken. This is supported by the number of signals in the decoupled ${ }^{13} \mathrm{C}$ spectra, showing individual signals for each carbon atom.

In contrast to the ${ }^{1} \mathrm{H}$ and ${ }^{13} \mathrm{C}$ data, ${ }^{19} \mathrm{~F}$ data of the anion $\mathrm{CF}_{3} \mathrm{SO}_{3}{ }^{-}$(OTf ${ }^{-}$) in THF- $\mathrm{d}_{8}$ and MeOD- $\mathrm{d}_{4}$ do not differ significantly. Neither an additional signal was found nor large chemical shifts differences between the solvents are observed $\left(\Delta \delta\left({ }^{19} \mathrm{~F}\right)_{\text {THF-MeOD }}=0.71 \mathrm{ppm}\right.$, cf. experimental section). The former would indicate an inner sphere complexation of the anion forming a Th(IV) complex with tenfold coordination. The latter would indicate an additional interaction between anion and solvent molecules which might lead to the breakdown of the symmetry. Based on the ${ }^{19} \mathrm{~F}$ chemical shifts a direct involvement of the anion in the breakdown of the ligand's symmetry in MeOD- $d_{4}$ cannot be proven. It is more likely that that the ligand's configuration in the complex is tied to the properties of the solvent. Thus, the focus of the following discussion relies on the solvent-complex interaction. 


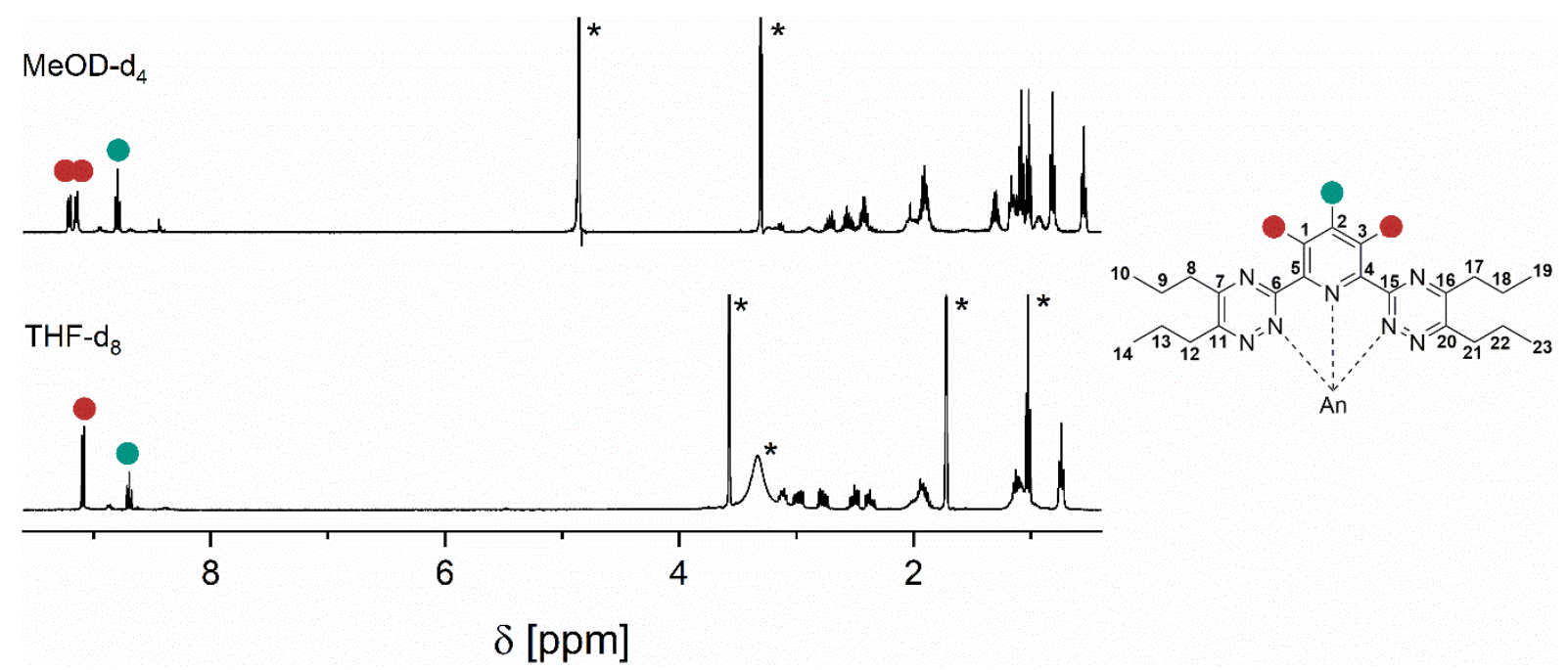

Figure $2^{1}{ }^{\mathrm{H}}$ NMR spectra $(400.13 \mathrm{MHz}, 300 \mathrm{~K})$ of $\left[\mathrm{Th}(\mathrm{nPr}-\mathrm{BTP})_{3}\right](\mathrm{OTf})_{4}\left(\left[\mathrm{Th}^{4+}\right]=10 \mathrm{mmolL}^{-1}\right)$ recorded in methanol-d $\mathrm{d}_{4}$ $\left(\right.$ MeOD- $\left.d_{4}\right)$ and tetrahydrofuran- $d_{8}\left(T H F-d_{8}\right)$. Solvent and water signals are marked with *.

\section{Influence of solvent polarity on the ligand's configuration}

Table 1 Chemical shifts of the ${ }^{1} \mathrm{H}$ and ${ }^{13} \mathrm{C}$ aromatic nuclei of the pyridine ring within the $\mathrm{nPr}-\mathrm{BTP}$ ligand for a variety of deuterated organic solvents ranked by their solvents polarity given as $\mathrm{E}_{\mathrm{T}}^{\mathrm{N}}$ values.

\begin{tabular}{|c|c|c|c|c|c|c|c|c|c|c|}
\hline & $\mathrm{E}_{\mathrm{T}}^{\mathrm{N}}$ ref 14 & $\mathrm{H}_{1}$ & $\mathrm{H}_{2}$ & $\mathrm{H}_{3}$ & $C_{1}$ & $C_{2}$ & $C_{3}$ & $\mathrm{C}_{4}$ & $C_{5}$ & config* \\
\hline $\mathrm{MeOD}-\mathrm{d}_{4}$ & 0.760 & 9.15 & 8.79 & 9.20 & 129.9 & 144.9 & 130.1 & 154.7 & 154.0 & a \\
\hline iPrOD-d8 & 0.549 & 9.05 & 8.77 & 9.14 & 128.7 & 143.1 & 128.6 & 154.0 & 152.6 & $\mathrm{a}$ \\
\hline \multirow{2}{*}{ CyHexol-d ${ }_{12}^{* *}$} & \multirow{2}{*}{0.509} & 9.32 & 8.95 & 9.40 & 128.9 & 143.1 & 129.4 & 154.2 & 152.8 & a \\
\hline & & 9.37 & 9.01 & 9.37 & 129.2 & 143.1 & 129.2 & 153.0 & 153.0 & s \\
\hline Acetonitrile- $d_{3}$ & 0.466 & 9.13 & 8.77 & 9.13 & 130.2 & 146.1 & 130.2 & 153.4 & 153.4 & s \\
\hline DMSO-d 6 & 0.444 & 8.54 & 8.26 & 8.54 & 124.9 & 138.6 & 124.9 & 153.6 & 153.6 & s \\
\hline DMF- $d_{7}$ & 0.386 & 8.66 & 8.35 & 8.66 & 125.6 & 139.2 & 125.6 & 153.7 & 153.7 & s \\
\hline Acetone- $d_{6}$ & 0.355 & 9.28 & 9.00 & 9.28 & 130.2 & 145.6 & 130.2 & 153.7 & 153.7 & s \\
\hline Pyridine- $d_{5}$ & 0.302 & 8.82 & 8.25 & 8.82 & 126.1 & 140.0 & 126.1 & 154.3 & 154.3 & s \\
\hline THF-d 8 & 0.207 & 9.09 & 8.69 & 9.09 & 129.9 & 144.5 & 129.9 & 154.0 & 154.0 & $\mathrm{~s}$ \\
\hline
\end{tabular}

To determine a correlation between ligand configuration in the complex and the solvent polarity, the $\left[\mathrm{Th}(\mathrm{nPr}-\mathrm{BTP})_{3}\right]^{4+}$ complex was studied in a range of deuterated organic solvents. Table 1 shows the respective chemical shifts of the pyridine ${ }^{1} \mathrm{H}$ and ${ }^{13} \mathrm{C}$ aromatic nuclei $\mathrm{H}_{1}-\mathrm{H}_{3}$ and $\mathrm{C}_{1}-\mathrm{C}_{5}$. The solvent polarity is given as an $\mathrm{E}_{\mathrm{T}}^{\mathrm{N}}$ value as described by Reichardt et al. ${ }^{14}$ (note that the actual solvent polarity may be slightly higher due to small amounts of water or $\mathrm{D}_{2} \mathrm{O}$ in the sample).

In polar protic solvents $\left(E_{T}^{N}\right.$ values $>0.5$ ), the formation of the asymmetric complex is favored. On the contrary, in less polar solvents (i. e. polar aprotic solvents, $E_{T}^{N}<0.5$ ) the symmetric complex forms preferably. Due to the symmetry of the coordinated ligands, $\mathrm{H}_{1} / \mathrm{H}_{3}, \mathrm{C}_{1} / \mathrm{C}_{3}$ and $\mathrm{C}_{4} / \mathrm{C}_{5}$ are chemically equivalent and therefore show only one signal in the respective spectra. Noteworthy are the large differences within the group of the polar aprotic solvents, leading to a separation in two categories: DMSO- $d_{6}$, DMF- $d_{7}$ and pyridine- $d_{5}$ on one hand and acetonitrile- $d_{3}$, acetone- $d_{6}$ and THF- $d_{8}$ the other hand, as evident from the $H_{1} / H_{3}$ shifts. The same trend is observed for $C_{1} / C_{3}$ and $C_{2}$. These disparities result from differences in the solvent-complex interaction. ${ }^{15-16}$ Cyclohexanol- $\mathrm{d}_{12}$ represents an exceptional case. With an $E_{T}^{N}$ value of 0.509 , it is at the boundary between polar protic and polar aprotic. This leads to the formation of a mixture of both complexes in a ratio 1:1.5 in favor of the asymmetric complex. 
The results show a clear relation between solvent polarity and the configuration of the BTP ligand in the complex. Electrostatic interactions between the complex and the solvent molecules via H-bonding are a possible explanation for the asymmetry. Breault et al. showed that the morphology of Fe(II) and $\mathrm{Ru}(\mathrm{II})$ tris-bipyridine complexes changes with the solvent's ability to form $\mathrm{H}$-bonds. ${ }^{17}$ They explain this behavior by a polarization of the aromatic rings, making them accept $\mathrm{H}$-bond from solvent molecules. The higher nuclear charge of the $\mathrm{Th}^{4+}$ ion causes a polarization of the aromatic rings, resulting in a strong solvent-complex interaction via $\mathrm{H}$-bonding in polar protic solvents.

\section{${ }^{1} \mathrm{H}-\mathrm{NMR}$ analysis of $\left[\mathrm{Th}(\mathrm{nPr}-\mathrm{BTP})_{3}\right]^{4+}$ in binary solvent mixtures}

To examine the influence of $\mathrm{H}$-bonding, $\left[\mathrm{Th}(\mathrm{nPr}-\mathrm{BTP})_{3}\right]^{4+}$ was studied in pyridine- $\mathrm{d}_{5} /$ methanol- $_{4}$ mixtures. This mixture provides adequate accessibility to the solvent polarity of approximately $0.5 .{ }^{18}$ This allows to compare the spectra in that solvent polarity range to spectra recorded in cyclohexanol- $\mathrm{d}_{12}$. Assuming that $\mathrm{H}$-bonding plays an important role in the ligand's configuration in the complex, the formation of either the symmetric or asymmetric complex should only depend on the methanol molar fraction.

Figure 3 shows the ${ }^{1} \mathrm{H}$ NMR spectra of $\left[\mathrm{Th}(\mathrm{nPr}-\mathrm{BTP})_{3}\right]^{4+}$ in different methanol- $\mathrm{d}_{4} /$ pyridine- $\mathrm{d}_{5}$ mixtures ranging from $\chi(\mathrm{MeOD})=0.196\left(E_{T}^{\mathrm{N}}=0.48\right)$ to $\chi(\mathrm{MeOD})=0.983\left(E_{\mathrm{T}}^{\mathrm{N}}=0.74\right)$. The left side displays the ${ }^{1} \mathrm{H}-\mathrm{NMR}$ spectra for the $\mathrm{E}_{\mathrm{T}}^{\mathrm{N}}$ values of $0.48,0.5$ and 0.52 . Contrary to cyclohexanol- $\mathrm{d}_{12}$, exclusive formation of the symmetric complex is observed. The right side shows the temporal evolution at $\chi(\mathrm{MeOD})=0.983\left(\mathrm{E}_{\mathrm{T}}^{\mathrm{N}}=0.74\right)$. Initially, eight $\mathrm{BTP}$ signals are observed. By analyzing ${ }^{1} \mathrm{H}-\mathrm{COSY}$ spectra, the signals are assigned to three different BTP species. The signals at $9.22 \mathrm{ppm}(\mathrm{d}), 9.15 \mathrm{ppm}(\mathrm{d})$ and 8.81 ppm (t) correspond to the asymmetric complex (cf. Table 1), with an intensity share of initially $58 \%$, increasing to $80 \%$ within $13 \mathrm{~d}$. The signals at $8.70 \mathrm{ppm}(\mathrm{d})$ and $8.17 \mathrm{ppm}(\mathrm{t})$ correspond to the symmetric complex, with an intensity share of initially $35 \%$, decreasing to $19 \%$. The signals at $8.65 \mathrm{ppm}$ (d), $8.42 \mathrm{ppm}(\mathrm{d})$ and $8.12 \mathrm{ppm}(\mathrm{t})$ are assigned to the preorganized free BTP ligand. The intensity of this signal set decreases from $7 \%$ to $<1 \%$ over time.
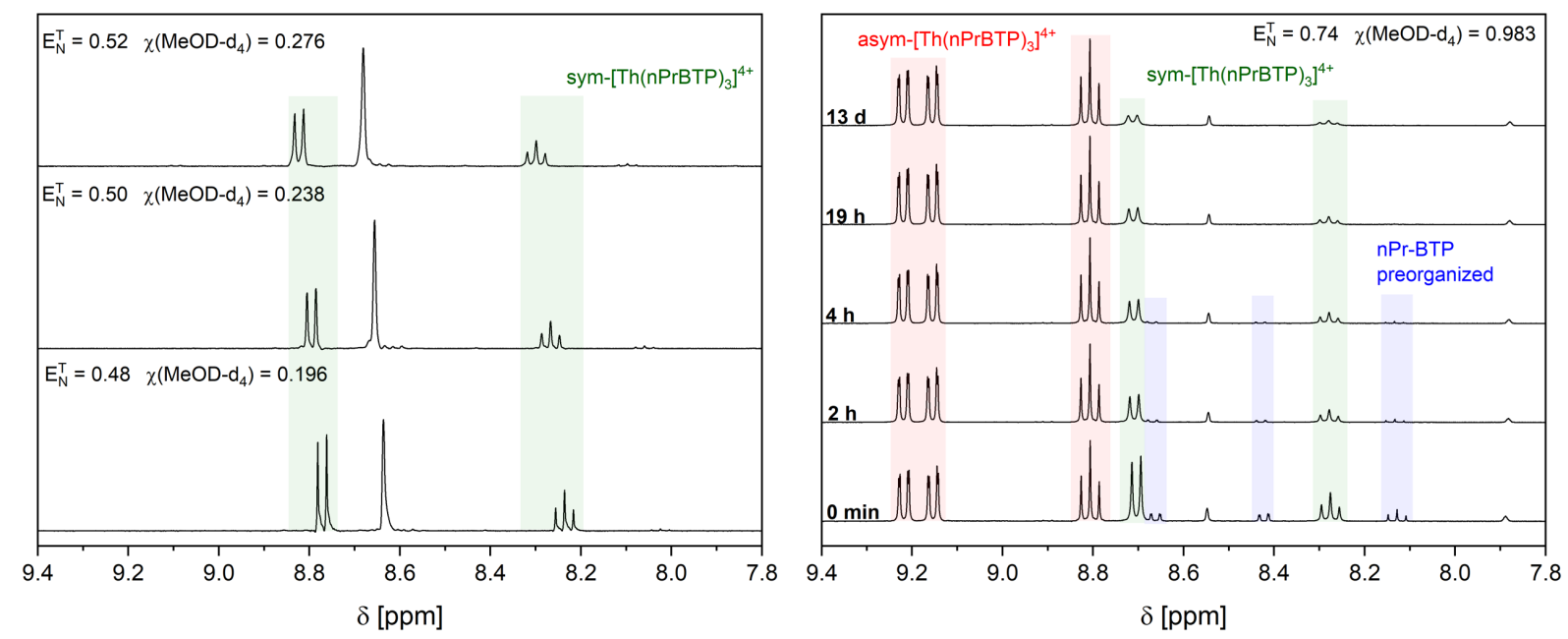

Figure $3^{1} \mathrm{H}-\mathrm{NMR}(400.13 \mathrm{MHz}, 300 \mathrm{~K})$ of $\left[\mathrm{Th}(\mathrm{nPr}-\mathrm{BTP})_{3}\right]^{4+}$ complexes $\left(\left[\mathrm{Th}^{4+}\right]=10 \mathrm{mmolL}^{-1}\right)$ in different pyridine- $\mathrm{d}_{5} / \mathrm{MeOD}^{-\mathrm{d}_{4}}$ mixtures in $\chi(\mathrm{MeOD})=0.276$ (left) and in $\chi(\mathrm{MeOD})=0.983$ (right).

\section{Pure solvents vs. binary mixtures}

Distinct differences between pure solvents and binary solvent mixtures of a given polarity are evident. While both symmetric and asymmetric complexes are formed in cyclohexanol- $d_{12}\left(E_{T}^{N}=0.509\right)$, only the symmetric complex is observed in pyridine/methanol mixtures of similar polarity $\left(0.48 \leq E_{T}^{N} \leq 0.52\right)$. Furthermore, the asymmetric complex is observed both in methanol $\left(E_{T}^{N}=0.76\right)$ and in propanol 
$\left(E_{T}^{N}=0.549\right)$. In contrast, both symmetric and asymmetric complexes are formed in a pyridine/methanol mixture with $\chi(\mathrm{MeOD})=0.983\left(E_{T}^{N}=0.74\right)$.

Clearly, the solvent polarity alone is not sufficient to explain the ligand's configuration. Rather, the ligand's configuration depends on the molecular properties of the single components of the binary mixture. Obviously, the asymmetric complex is only formed in systems containing adequate concentrations of $\mathrm{H}$-bond donors such as alcohols.

\section{Theoretical investigation of the complex structure}

The previous discussion of the NMR data has avoided the question concerning the structure of each complex species. For the symmetrical complex, the NMR data suggest a complex structure similar to that observed for the trivalent lanthanide and actinide ions. ${ }^{11}$ In case of the asymmetrical complex, the NMR data may be explained by two different structures (cf. Figure 4). Asymmetry in the flip configuration is caused by torsion of one 1,2,4-triazinyl ring around the $C_{\text {pyr }}-C_{\text {triazin }}$ bond, as observed for the free ligand. ${ }^{19}$ For the asym configuration, asymmetry is a result of a different spatial arrangement of the propyl moieties.

The three complexes were examined using quantum mechanical calculations. Energies and bond lengths of each complex are given in Table 2. The DFT-optimized complex structures are displayed in Figure 5. $\mathrm{N}-\mathrm{Th}^{4+}$ bond distances of the sym complex are $\mathrm{r}\left(\mathrm{Th}-\mathrm{N}_{\text {pyr }}\right)=265 \mathrm{pm}$ and $\mathrm{r}\left(\mathrm{Th}-\mathrm{N}_{\text {triazin }}\right)=262 \mathrm{pm}$. Average $\mathrm{N}-\mathrm{Ln}^{3+}$ bond lengths of $256 \mathrm{pm}$ were determined by EXAFS for BTP complexes with $\operatorname{Ln}(\mathrm{III})$ having similar ionic radii such as Dy(III) $\left(r\left(\mathrm{Dy}^{3+}\right)=108 \mathrm{pm}\right)$ and $\mathrm{Ho}(\mathrm{III})\left(\mathrm{r}\left(\mathrm{Ho}^{3+}\right)=107 \mathrm{pm}\right) .{ }^{20-22}$ The sym configuration is energetically favored. Therefore, it serves as a reference for the following discussion.

The DFT-optimized structure of flip configuration shows that both triazinyl rings are contorted. The non-rotated ring inclines towards the metal ion, whereas the rotated aromatic ring faces away from the complex center. The Th- $\mathrm{N}_{\text {triazin }}$ bond length differ significantly, $259 \mathrm{pm}$ and $285 \mathrm{pm}$. A significant increase of $\Delta \mathrm{E}_{\text {bind }}=225.2 \mathrm{kJmol}^{-1}$ is observed for the flip configuration, originating from the unfavorable proximity of the inward propyl moiety to the metal ion. Solvent and vibrational corrections reduce this energy difference to $\Delta \mathrm{G}_{\text {flip-sym }}=166.3 \mathrm{kJmol}^{-1}$.
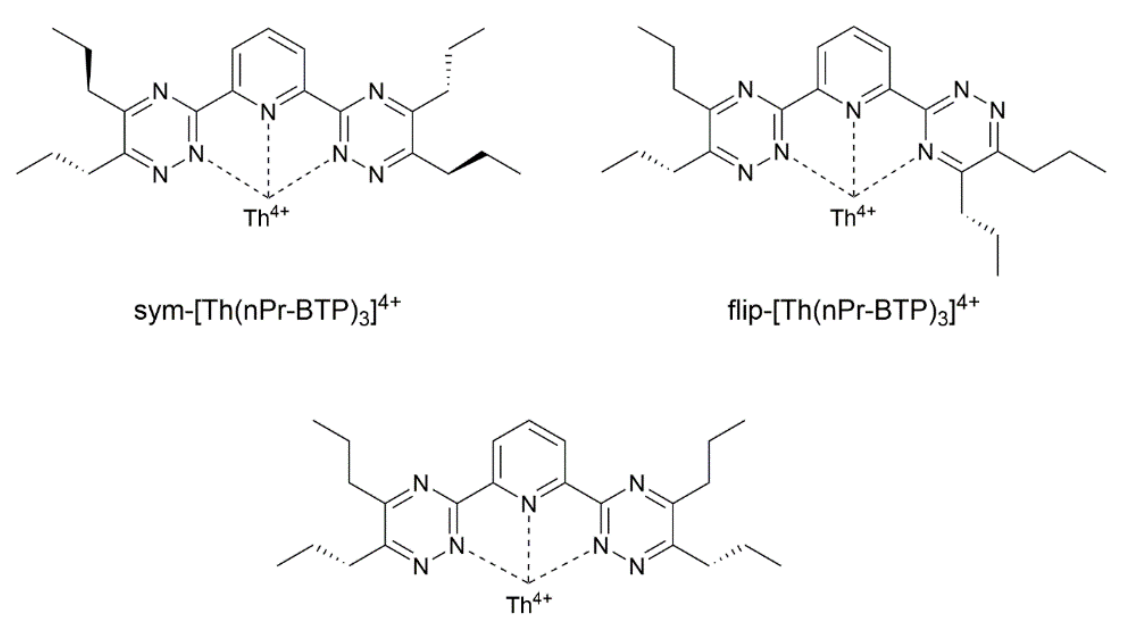

asym- $\left[\mathrm{Th}(\mathrm{nPr}-\mathrm{BTP})_{3}\right]^{4+}$

Figure 4 Proposed structures of $\left[\mathrm{Th}(\mathrm{nPr}-\mathrm{BTP})_{3}\right]^{4+}$ based on the ${ }^{1} \mathrm{H}$ and ${ }^{13} \mathrm{C}-\mathrm{NMR}$ analysis. 


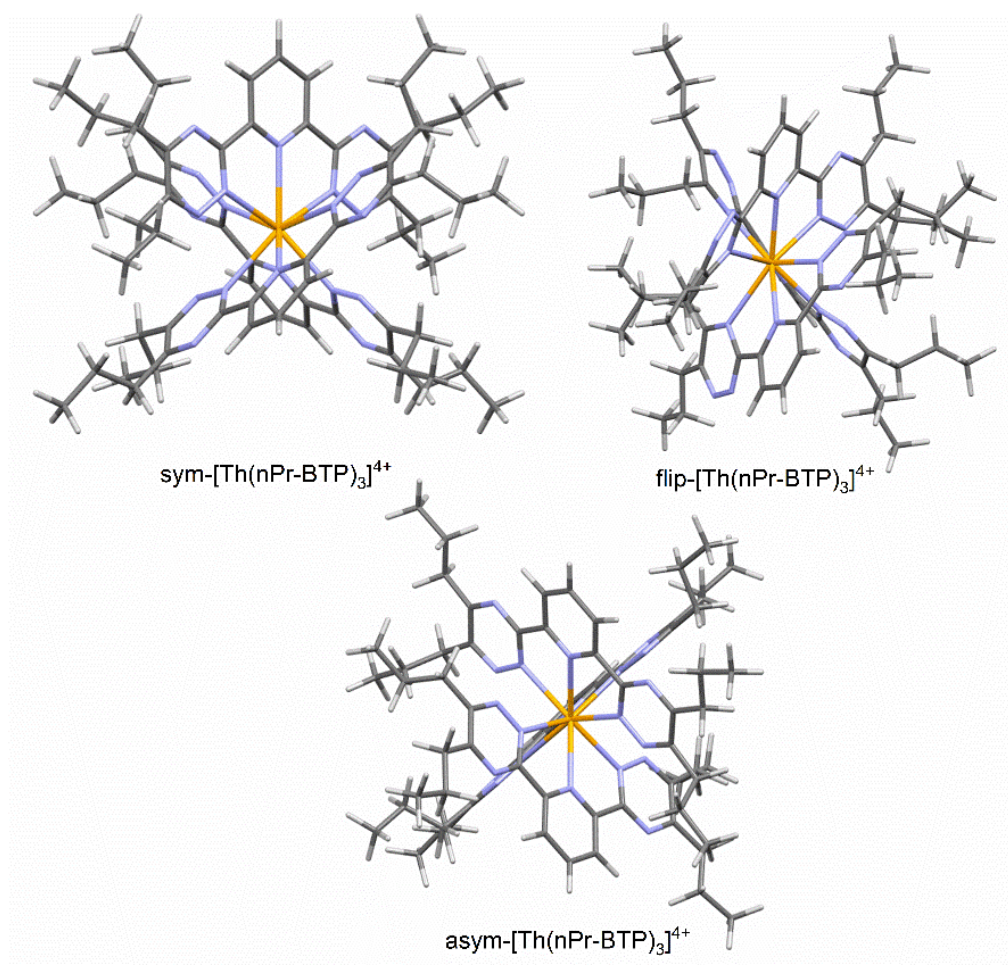

Figure 5 DFT-optimized complex structures (functional B3LYP, basis set: def2-TVZP) of the proposed $\left.[\text { Th(nPr-BTP) }]_{3}\right]^{4+}$ based on the ${ }^{1} \mathrm{H}$ and ${ }^{13} \mathrm{C}-\mathrm{NMR}$ analysis.

The symmetry in the asym configuration is broken by the rotation of a propyl moiety. The inner coordination sphere remains unchanged compared to the asym configuration. Th- $\mathrm{N}$ bond distances are $r\left(T h-N_{\text {triazin }}\right)=265$ pm vs. $264 \mathrm{pm}$ and $r\left(T h N_{\text {pyr }}\right)=262$ pm vs. 261 pm, respectively. Including solvent effects and vibrational corrections, the Gibbs energy difference $\Delta G_{\text {asym sym }}$ is $7.8 \mathrm{kJmol}^{-1}$ due to repulsive forces between the propyl moieties.

Table 2 Energies and Th- $\mathrm{N}$-bond lengths for the three complex configurations shown in Figure 1.

\begin{tabular}{cccc}
{$\left[\mathrm{Th}(\mathrm{nPr}-\mathrm{BTP})_{3}\right]^{4+}$} & sym & flip & asym \\
\hline $\mathrm{E}_{\text {bind }}\left[\mathrm{kJmol}^{-1}\right]$ & -4547.7 & -4322.5 & -4546.7 \\
$\mathrm{E}_{\text {cosmo }}\left[\mathrm{kJmol}^{-1}\right]$ & -1434.1 & -1482.7 & -1434.1 \\
$\mathrm{E}_{\text {zp }}\left[\mathrm{kJmol}^{-1}\right]$ & 2972 & 2969 & 2979 \\
$\mathrm{E}_{\mathrm{H}}\left[\mathrm{kJmol}^{-1}\right]$ & 3171.0 & 3167.9 & 3154.7 \\
$\mathrm{E}_{\text {-Ts }}\left[\mathrm{kJmol}{ }^{-1}\right]$ & -518.1 & -522.3 & -502.0 \\
$\Delta \mathrm{G}$ & - & 166.3 & 7.8 \\
\hline $\mathrm{r}\left(\mathrm{Th}-\mathrm{N}_{\text {pyr }}\right)[\mathrm{pm}]$ & 265 & 261 & 264 \\
$\mathrm{r}\left(\mathrm{Th}-\mathrm{N}_{\text {triazin }}\right)[\mathrm{pm}]$ & 262 & $259^{\mathrm{a}} / 285^{\mathrm{b}}$ & 261
\end{tabular}

Comparing $\Delta \mathrm{G}_{\text {flip-sym }}$ to $\Delta \mathrm{G}_{\text {asym-sym, }}$ the energy difference largely excludes the flip configuration. Hence, the asym configuration most likely represents the asymmetric $\left[\mathrm{Th}(\mathrm{nPr}-\mathrm{BTP})_{3}\right]^{4+}$ species. The small energy difference can be compensated by interaction with solvent molecules. Figure 6 displays the impact of the introduction of one solvent molecule on the binding energy of the sym complex at varied Th-solvent distances. For the calculations, methanol as polar protic solvent and acetonitrile as polar aprotic solvent were used as representatives. The distance $r_{\text {Th solv }}$ was increased in steps of $25 \mathrm{pm}$ from 
$300 \mathrm{pm}$ to $600 \mathrm{pm}$. The energy values $E_{\text {tot }}$ are given in the supporting information. For both solvents, the energy rises significantly between $300 \mathrm{pm}$ and $450 \mathrm{pm}$. The energetic minimum for the acetonitrile is located at $525 \mathrm{pm}$. In contrast, two minima at $500 \mathrm{pm}$ and $575 \mathrm{pm}$ are found for methanol. Between those minima, the energy of the complex species is slightly increased by $0.26 \mathrm{kJmol}^{-1}$ at $525 \mathrm{pm}$ and $0.75 \mathrm{~kJ} \mathrm{~mol}^{-1}$ at $550 \mathrm{pm}$, respectively. The first minimum is induced by a hydrogen bond between the solvent and the ligand. However, the shallow energy barrier between the two minima is not representative, as additional solvent molecules will increase the energy barrier. Additionally, the energetic impact of one methanol molecule at $r_{\text {Th-solv }}=500 \mathrm{pm}$ on the asym complex was probed. The DFT results show that the energy difference between asym and sym complex is further reduced from $7.8 \mathrm{kJmol}^{-1}$ to $3.6 \mathrm{kJmol}^{-1}$. Hence, the formation of the asym structure encourages the invasion of solvent molecules. These energy considerations in combination with the NMR data suggest the formation of the asym- $\left[\operatorname{Th}(n \operatorname{Pr} B T P)_{3}\right]^{4+}$ complex in polar protic solvents.

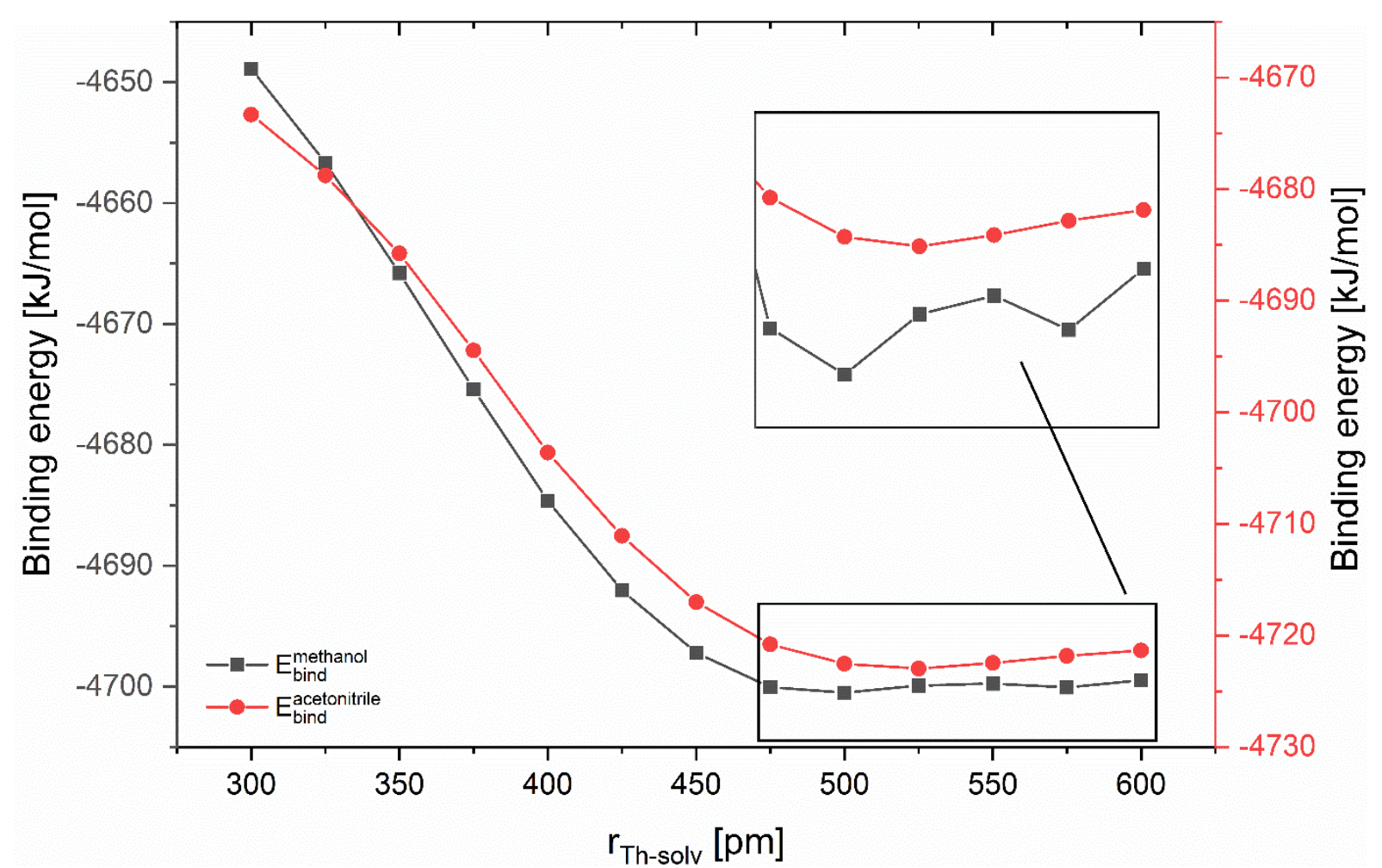

Figure 6 Influence of polar protic and polar aprotic solvent molecules on the binding energy of $\left[\mathrm{Th}(\mathrm{nPr}-\mathrm{BTP})_{3}\right]^{4+}$. DFT calculations were performed using structures given Figure 4 with def2-TVZP basis set and B3LYP functional. 


\section{${ }^{15} \mathrm{~N}-\mathrm{NMR}$ analysis}

Table $3{ }^{15} \mathrm{~N}-\mathrm{NMR}$ chemical shifts $(40.58 \mathrm{MHz}, 300 \mathrm{~K})$ of the pyridine nitrogen $\mathrm{N}_{1}$ and the ${ }^{15} \mathrm{~N}$ labeled nitrogen atoms $\mathrm{N}_{2}-\mathrm{N}_{5}$.

$\begin{array}{cccccccc} & & & \\ \end{array}$

To directly probe the Th(IV)-N bond, $\left[\mathrm{Th}(\mathrm{nPr}-\mathrm{BTP})_{3}\right]^{4+}$ complexes were prepared in a variety of solvents using ${ }^{15} \mathrm{~N}$ labeled $\mathrm{nPr}$-BTP ligand. Table 3 shows the ${ }^{15} \mathrm{~N}-\mathrm{NMR}$ chemical shifts of the pyridine nitrogen atom $\mathrm{N}_{1}$ and the ${ }^{15} \mathrm{~N}$ labeled nitrogen atoms $\mathrm{N}_{2}-\mathrm{N}_{5}$ of the 1,2,4-trizinyl ring (position 1 and 2 are labeled). For the pyridine nitrogen atom $\mathrm{N}_{1}$, chemical shifts range from $286 \mathrm{ppm}$ to $313 \mathrm{ppm}$. The correlation spectra differ only in the number of coupling partners. Based on these results, we assume that the Th- $\mathrm{N}_{1}$ bonding properties in both complexes are nearly identical.

In polar aprotic solvents, one doublet is found for each $\mathrm{N}_{2} / \mathrm{N}_{4}$ and $\mathrm{N}_{3} / \mathrm{N}_{5}$ pair, which is in agreement with the sym configuration. In polar protic solvents, four ${ }^{15} \mathrm{~N}$ doublets are observed for $\mathrm{N}_{2}-\mathrm{N}_{5}$. The chemical shift disparities between the nitrogen atom pairs $N_{3} / N_{5}$ and $N_{2} / N_{4}$ are very small, supporting that asymmetry is caused by a reorganization of the $\mathrm{nPr}$ side chains rather a rotation of one 1,2,4triazinyl rings. Only minor differences between sym and the asym configuration are observed, proving that the bonding properties in both complexes are similar.

Additional information of the bonding properties between the nitrogen atoms and the $\mathrm{Th}^{4+}$ ion is gathered by comparing the ${ }^{15} \mathrm{~N}$ chemical shifts to those of the free ligand, the diamagnetic $\left[\mathrm{Lu}(\mathrm{nPr}-\mathrm{BTP})_{3}\right]^{3+}$ complex and the weakly paramagnetic $\left[\mathrm{Am}(\mathrm{nPr}-\mathrm{BTP})_{3}\right]^{3+}$ complex. Compared to weakly paramagnetic or diamagnetic lanthanide ions, $\mathrm{N}_{1}$ and $\mathrm{N}_{2} / \mathrm{N}_{4}$ are upshifted by approximately $300 \mathrm{ppm}$ in the Am(III) complex. ${ }^{11}$ This pronounced shift gives evidence for an increased covalent contribution to the An(III)-N bond. Since no such shift is observed for the $\mathrm{Th}^{4+}$ complex, the Th(IV)-N interaction is proved to be predominantly electrostatic. In fact, the ${ }^{15} \mathrm{~N}$ chemical shifts of the complexed nitrogen atoms $\mathrm{N}_{1}$ and $\mathrm{N}_{2} / \mathrm{N}_{4}$ differ only slightly from the ${ }^{15} \mathrm{~N}$ shifts of the free ligand and the Lu(III) BTP complex ( $\Delta \delta \approx 20-25 \mathrm{ppm}$ in both cases), confirming the high electrostatic nature of the Th(IV)-N bond. 


\section{Conclusion}

The $\left[\mathrm{Th}(\mathrm{nPr}-\mathrm{BTP})_{3}\right]^{4+}$ complex was prepared and studied by NMR in solution. Unexpectedly, depending on the solvent's ability to actively form hydrogen bonds, two different complex structures were observed. In polar aprotic solvents, a symmetric complex forms which is isostructural with $\left[\mathrm{M}(\mathrm{R}-\mathrm{BTP})_{3}\right]^{3+}$ complexes studied earlier. In contrast, an asymmetric complex forms in polar protic solvents. Key difference between these structures lies within the spatial arrangement of the $\mathrm{nPr}$ moieties. Quantum chemical calculations explain this difference by differences in the interaction of solvent molecules with the BTP ligands.

Important information on bonding properties were obtained by ${ }^{15} \mathrm{~N}-\mathrm{NMR}$. In contrast to the respective Am(III) complex showing a significant covalent contribution, the Th(IV)-BTP interaction is mainly electrostatic, as expected for a highly charged diamagnetic $f$ element ion.

Finally, this study serves as a valuable reference for future NMR studies of paramagnetic tetravalent actinides $\mathrm{U}^{4+}, \mathrm{Pu}^{4+}$ and $\mathrm{Np}^{4+}$.

\section{Experimental section}

\section{Materials and methods}

Deuterated solvents were purchased from Euriso-Top GmbH. Chemicals for synthesis were purchased from VWR International and used as-is. nPr-BTP and ${ }^{15} \mathrm{~N}$ labeled $\mathrm{nPr}-\mathrm{BTP}$ were synthesized according to literature. ${ }^{11}$

NMR spectra were recorded on a Bruker Avance III 400 spectrometer operating at $400.13 \mathrm{MHz}$ for ${ }^{1} \mathrm{H}$, $100.63 \mathrm{MHz}$ for ${ }^{13} \mathrm{C}, 376.50 \mathrm{MHz}$ for ${ }^{19} \mathrm{~F}$ and $40.58 \mathrm{MHz}$ for ${ }^{15} \mathrm{~N}$ at $300 \mathrm{~K}$ (exception: cyclohexanol- $\mathrm{d}_{12}$ at $348 \mathrm{~K})$. The spectrometer was equipped with a broadband observe probe (BBFOplus) with direct $\mathrm{X}$ magnetization detection for proton and heteronuclear detection experiments. Chemical shifts are referenced internally to TMS $(\delta(\mathrm{TMS})=0 \mathrm{ppm})$ for ${ }^{1} \mathrm{H}$ and ${ }^{13} \mathrm{C}$, to $\mathrm{CFCl}_{3}\left(\delta\left(\mathrm{CFCl}_{3}\right)=0 \mathrm{ppm}\right)$ for ${ }^{19} \mathrm{~F}$ and to ${ }^{15} \mathrm{NH}_{4} \mathrm{Cl}$ with $\delta\left({ }^{15} \mathrm{NH}_{4} \mathrm{Cl}\right)=0 \mathrm{ppm}$ for ${ }^{15} \mathrm{~N}$. For all spectra, standard Bruker pulse sequences were used. $1 \mathrm{D}$ spectra of ${ }^{1} \mathrm{H},{ }^{13} \mathrm{C}$ and ${ }^{15} \mathrm{~N}$ were recorded with $32 \mathrm{k}$ data points and are zero filled to $64 \mathrm{k}$ data points. ${ }^{19} \mathrm{~F}$ spectra were recorded at higher resolution with $64 \mathrm{k}$ data points. ${ }^{15} \mathrm{~N}$ data at natural abundance were obtained from high resolution ${ }^{1} \mathrm{H},{ }^{15} \mathrm{~N}-\mathrm{HMQC}$ spectra with a resolution of $4 \mathrm{k}$ data points in the indirect dimension. Signal multiplicity was determined as s (singlet), $d$ (doublet), $t$ (triplet), q (quartet), quin (quintet), sex (sextet), sept (septet), $m$ (multiplet) and br. $s$ (broad signal).

Structure optimization were performed on the density functional theory (DFT) level employing the B3LYP functional ${ }^{23}$ as implemented in TURBOMOLE ${ }^{24}$. The Th(IV) ion was described by the $\mathrm{ECP} 0 \mathrm{MWB}^{25}$ small-core pseudo potential with corresponding basis sets of triple-zeta quality. For all remaining atoms, the def2-TVZP ${ }^{26}$ basis set was used. Binding energies for the optimized complex structures were obtained by $E_{\text {bind }}=E_{\text {tot }}-E_{\text {solv }}-E_{T h}-3 E_{B T P}$, where $E_{\text {tot }}, E_{\text {solv }}, E_{T h}, E_{B T P}$, are total DFT energies of the complex, solvent molecule, thorium ion and $\mathrm{nPr}-\mathrm{BTP}$, respectively. From the binding energies, the Gibbs energies were determined by taking vibrational $\left(E_{\text {vib }}\right)$ and solvent $\left(E_{\text {cosmo }}\right)$ energies into account. The latter were computed using the conductor-like screening model COSMO ${ }^{27}$. A cavity radius of $192 \mathrm{pm}$ was used for $T h(\mathrm{IV}) . \Delta \mathrm{G}=\Delta \mathrm{E}_{\text {bind }}+\Delta \mathrm{E}_{\text {vib }}+\Delta \mathrm{E}_{\text {cosmo }}$.

\section{Synthesis of the $\mathrm{Th}(\mathrm{OTf})_{4}$ stock solution}

$206.38 \mathrm{mg} \mathrm{Th}\left(\mathrm{NO}_{3}\right)_{4} \cdot 5 \mathrm{H}_{2} \mathrm{O}(0.362 \mathrm{~mol})$ were dissolved in $2 \mathrm{~mL}$ milliQ-water in a $4 \mathrm{~mL}$ glass vial. $400 \mu \mathrm{L}$ $10 \mathrm{molL}^{-1} \mathrm{NaOH}$ were added initially to the solution. The vial was then centrifuged and $10 \mathrm{molL}^{-1} \mathrm{NaOH}$ was added until no further precipitation was observed. After one hour, the precipitate was centrifuged, 
the supernatant was removed and the precipitate was washed twice with $2 \mathrm{~mL} 0.05 \mathrm{molL}^{-1} \mathrm{NaOH}$. Then, $2 \mathrm{~mL}$ milliQ-water were added, and the precipitate was slowly dissolved by stepwise addition of concentrated HOTf $(170 \mu \mathrm{L}) . \mathrm{c}\left(\mathrm{Th}^{4+}\right)=129.75 \mathrm{mmolL}^{-1}$.

\section{Synthesis of $\left[\mathrm{Th}(\mathrm{nPr}-\mathrm{BTP})_{3}\right](\mathrm{OTf})_{4}$}

General procedure. $\left.46.24 \mu \mathrm{L}(6 \mu \mathrm{mol} \text { Th(OTf) })_{4}, 1 \mathrm{eq}\right)$ of the $\mathrm{Th}^{4+}$-stock solution and $200 \mu \mathrm{L} \mathrm{D}_{2} \mathrm{O}$ were evaporated in a $2 \mathrm{~mL}$ glass vial for $30 \mathrm{~min}$. $7.30 \mathrm{mg}$ (18 $\mu \mathrm{mol}, 3 \mathrm{eq}) \mathrm{nPr}$-BTP were dissolved in $600 \mu \mathrm{L}$ deuterated solvent and the ligand solution was added to the Th(OTf $)_{4}$ residue. The solution was then transferred into a high-resolution NMR tube.

asym-[Th(nPr-BTP) $\left.)_{3}\right](\mathrm{OTf})_{4} .{ }^{1} \mathrm{H}-\mathrm{NMR} \quad\left(400.13 \mathrm{MHz}, 300 \mathrm{~K}, \mathrm{MeOD}_{-} \mathrm{d}_{4}\right) \delta[\mathrm{ppm}]=9.20(\mathrm{~d}$, $\left.{ }^{3} \mathrm{~J}\left(\mathrm{H}_{2}-\mathrm{H}_{3}\right)=8.0 \mathrm{~Hz}, 1 \mathrm{H}, \mathrm{H}-3\right), 9.15\left(\mathrm{~d},{ }^{3} \mathrm{~J}\left(\mathrm{H}_{1}-\mathrm{H}_{2}\right)=8.0 \mathrm{~Hz}, 1 \mathrm{H}, \mathrm{H}-1\right), 8.79\left(\mathrm{dd},{ }^{3} \mathrm{~J}\left(\mathrm{H}_{1}-\mathrm{H}_{2}\right) / \mathrm{J}\left(\mathrm{H}_{2}-\mathrm{H}_{3}\right)=8.0 \mathrm{~Hz}\right.$, $1 \mathrm{H}, \mathrm{H}-2), 2.78-2.70(\mathrm{~m}, 1 \mathrm{H}, \mathrm{H}-17 \mathrm{a}), 2.60-2.52(\mathrm{~m}, 1 \mathrm{H}, \mathrm{H}-17 \mathrm{~b}), 2.43\left(\mathrm{t},{ }^{3} \mathrm{~J}\left(\mathrm{H}_{12}-\mathrm{H}_{13}\right)=7.8 \mathrm{~Hz}, 2 \mathrm{H}, \mathrm{H}-12\right)$, 1.99-1.86 (m, 6H, H-8/H-9/H-21), $1.30\left(\mathrm{sex}^{3} \mathrm{~J}\left(\mathrm{H}_{17}-\mathrm{H}_{18}\right)=7.6 \mathrm{~Hz}^{3} \mathrm{~J}\left(\mathrm{H}_{18}-\mathrm{H}_{19}\right)=7.3 \mathrm{~Hz}, 2 \mathrm{H}, \mathrm{H}-18\right), 1.14-$ $1.10(\mathrm{~m}, 9 \mathrm{H}, \mathrm{H}-22), 1.03\left(\mathrm{t},{ }^{3} \mathrm{~J}\left(\mathrm{H}_{22}-\mathrm{H}_{23}\right)=7.6 \mathrm{~Hz}, 3 \mathrm{H}, \mathrm{H}-23\right), 0.97-0.87(\mathrm{~m}, 1 \mathrm{H}, \mathrm{H}-13 \mathrm{a}), 0.88-$ $0.76(\mathrm{~m}, 1 \mathrm{H}, \mathrm{H}-13 \mathrm{~b}), 0.82\left(\mathrm{t},{ }^{3} \mathrm{~J}\left(\mathrm{H}_{18}-\mathrm{H}_{19}\right)=7.3 \mathrm{~Hz}, 3 \mathrm{H}, \mathrm{H}-19\right), 0.53\left(\mathrm{t},{ }^{3} \mathrm{~J}\left(\mathrm{H}_{13}-\mathrm{H}_{14}\right)=7.3 \mathrm{~Hz}, 3 \mathrm{H}, \mathrm{H}-\right.$ 14).

${ }^{13} \mathrm{C}$-NMR (100.63 MHz, 300 K, MeOD-d 4$) \delta[p p m]=167.1\left(C_{q}, C-11\right), 166.7\left(C_{q}, C-16\right), 162.5\left(C_{q}, C-6\right)$, $161.3\left(C_{q}, C-7\right), 160.4\left(C_{q}, C-20\right), 159.6\left(C_{q}, C-15\right), 153.4\left(C_{q}, C-4\right), 152.7\left(C_{q}, C-5\right), 143.5\left(C_{t}, C-2\right), 128.7$ $\left(C_{t}, C-3\right), 128.6\left(C_{t}, C-1\right), 34.7\left(C_{s}, C-8\right), 34.2\left(C_{s}, C-21\right), 33.4\left(C_{s}, C-17\right), 33.3\left(C_{s}, C-12\right), 20.2\left(C_{s}, C-13\right)$, $20.1\left(C_{s}, C-18\right), 19.1\left(C_{s}, C-22\right), 18.9\left(C_{s}, C-9\right), 12.9\left(C_{p}, C-14\right), 12.7\left(C_{p}, C-10\right), 12.5\left(C_{p}, C-23\right), 12.4\left(C_{p}\right.$, C-19).

${ }^{15} \mathrm{~N}-\mathrm{NMR}\left(40.58 \mathrm{MHz}, 300 \mathrm{~K}, \mathrm{MeOD}-\mathrm{d}_{4}\right) \delta[\mathrm{ppm}]=387\left(\mathrm{~d},{ }^{1} \mathrm{~J}\left(\mathrm{~N}_{2}-\mathrm{N}_{3}\right)=20.8 \mathrm{~Hz}, \mathrm{~N}-3\right), 386(\mathrm{~d}$, $\left.{ }^{1} \mathrm{~J}\left(\mathrm{~N}_{4}-\mathrm{N}_{5}\right)=20.8 \mathrm{~Hz}, \mathrm{~N}-5\right), 327\left(\mathrm{~d},{ }^{1} \mathrm{~J}\left(\mathrm{~N}_{2}-\mathrm{N}_{3}\right)=20.8 \mathrm{~Hz}, \mathrm{~N}-2\right), 325\left(\mathrm{~d},{ }^{1} \mathrm{~J}\left(\mathrm{~N}_{4}-\mathrm{N}_{5}\right)=20.8 \mathrm{~Hz}, \mathrm{~N}-4\right), 287(\mathrm{~N}-1)^{*}$.

*Value taken from an ${ }^{1} \mathrm{H},{ }^{15} \mathrm{~N}-\mathrm{HMQC}$ spectrum

${ }^{19}$ F-NMR (376.50 MHz, $\left.300 \mathrm{~K}, \mathrm{MeOD}-\mathrm{d}_{4}\right) \delta[\mathrm{ppm}]=-79.99\left(\mathrm{CF}_{3} \mathrm{SO}_{3}{ }^{-}\right)$.

sym-[Th(nPr-BTP) $)_{3}$ (OTf) 4. $^{1}{ }^{1}$-NMR $\left(400.13 \mathrm{MHz}, 300 \mathrm{~K}\right.$, THF- $\left.\mathrm{d}_{8}\right) \delta[\mathrm{ppm}]=9.09\left(\mathrm{~d},{ }^{3} \mathrm{~J}\left(\mathrm{H}_{1 / 3}-\mathrm{H}_{2}\right)=7.9 \mathrm{~Hz}\right.$, $2 \mathrm{H}, \mathrm{H}-1 / 3), 8.70\left(\mathrm{t},{ }^{3} \mathrm{~J}\left(\mathrm{H}_{1 / 3}-\mathrm{H}_{2}\right)=7.9 \mathrm{~Hz}, 1 \mathrm{H}, \mathrm{H}-2\right), 3.02-2.94(\mathrm{~m}, 2 \mathrm{H}, \mathrm{H}-12 \mathrm{a}), 2.81-2.73(\mathrm{~m}, 2 \mathrm{H}, \mathrm{H}-12 \mathrm{~b})$, 2.54-2.47 (m, 2H, H-8a), 2.41-2.33 (m, 2H, H-8b), 2.04-1.84 (m, 8H, H-9/H-13), $1.02(\mathrm{t}$, $\left.{ }^{3} \mathrm{~J}\left(\mathrm{H}_{13}-\mathrm{H}_{14}\right)=7.3 \mathrm{~Hz}, 6 \mathrm{H}, \mathrm{H}-14\right), 0.74\left(\mathrm{t},{ }^{3} \mathrm{~J}\left(\mathrm{H}_{9}-\mathrm{H}_{10}\right)=7.3 \mathrm{~Hz}, 6 \mathrm{H}, \mathrm{H}-10\right)$.

${ }^{13} \mathrm{C}-\mathrm{NMR}\left(100.63 \mathrm{MHz}, 300 \mathrm{~K}, \mathrm{THF}-\mathrm{d}_{8}\right) \delta[\mathrm{ppm}]=169.1\left(\mathrm{C}_{q}, \mathrm{C}-7\right), 161.9\left(\mathrm{C}_{q}, \mathrm{C}-6 / \mathrm{C}-11\right), 154.0\left(\mathrm{C}_{q}, \mathrm{C}-4 / 5\right)$, $144.5\left(C_{t}, C-2\right), 129.9\left(C_{t}, C\right.$ 1/3), $36.8\left(C_{s}, C-8\right), 35.0\left(C_{s}, C-12\right), 21.0\left(C_{s}, C-9\right), 19.4\left(C_{s}, C 13\right), 14.2\left(C_{p}\right.$, C-10), $14.0\left(C_{p}, C-14\right)$.

${ }^{15} \mathrm{~N}-\mathrm{NMR}\left(40.58 \mathrm{MHz}, 300 \mathrm{~K}, \mathrm{THF}-\mathrm{d}_{8}\right) \delta[\mathrm{ppm}]=379\left(\mathrm{~d},{ }^{1} \mathrm{~J}\left(\mathrm{~N}_{2}-\mathrm{N}_{3}\right)=20.8 \mathrm{~Hz}, \mathrm{~N}-3\right), 318(\mathrm{~d}$, $\left.{ }^{1} \mathrm{~J}\left(\mathrm{~N}_{2}-\mathrm{N}_{3}\right)=20.8 \mathrm{~Hz}, \mathrm{~N}-2\right), 286(\mathrm{~N}-1)^{*}$.

*Value taken from an ${ }^{1} \mathrm{H},{ }^{15} \mathrm{~N}-\mathrm{HMQC}$ spectrum

${ }^{19} \mathrm{~F}-\mathrm{NMR}\left(376.50 \mathrm{MHz}, 300 \mathrm{~K}, \mathrm{THF}-\mathrm{d}_{8}\right) \delta[\mathrm{ppm}]=-79.28\left(\mathrm{CF}_{3} \mathrm{SO}_{3}{ }^{-}\right)$.

\section{Conflicts of interest}

There are no conflicts to declare.

\section{Notes and references}


1. Panak, P. J.; Geist, A., Complexation and Extraction of Trivalent Actinides and Lanthanides by Triazinylpyridine N-Donor Ligands. Chem. Rev. 2013, 113 (2), 1199-1236.

2. Ekberg, C.; Fermvik, A.; Retegan, T.; Skarnemark, G.; Foreman, M. R. S.; Hudson, M. J.; Englund, S.; Nilsson, M., An overview and historical look back at the solvent extraction using nitrogen donor ligands to extract and separate An(III) from Ln(III). Radiochim. Acta 2008, 96 (4-5), 225-233.

3. Panak, P. J.; Geist, A., Recent progress in trivalent actinide and lanthanide solvent extraction and coordination chemistry with triazinylpyridine N-donor ligands. Solvent Extr. Ion Exch. 2020, (accepted).

4. Foreman, M. R. S.; Hudson, M. J.; Drew, M. G. B.; Hill, C.; Madic, C., Complexes formed between the quadridentate, heterocyclic molecules 6,6'-bis-(5,6-dialkyl-1,2,4-triazin-3-yl)-2,2'-bipyridine (BTBP) and lanthanides(iii): implications for the partitioning of actinides(iii) and lanthanides(iii). Dalton Trans. 2006, (13), 1645-1653.

5. Afsar, A.; Laventine, D. M.; Harwood, L. M.; Hudson, M. J.; Geist, A., Utilizing electronic effects in the modulation of BTPhen ligands with respect to the partitioning of minor actinides from lanthanides. Chem. Commun. 2013, 49 (76), 8534-8536.

6. Lewis, F. W.; Harwood, L. M.; Hudson, M. J.; Drew, M. G. B.; Hubscher-Bruder, V.; Videva, V.; Arnaud-Neu, F.; Stamberg, K.; Vyas, S., BTBPs versus BTPhens: Some Reasons for Their Differences in Properties Concerning the Partitioning of Minor Actinides and the Advantages of BTPhens. Inorg. Chem. 2013, 52 (9), 4993-5005.

7. Zaytsev, A. V.; Bulmer, R.; Kozhevnikov, V. N.; Sims, M.; Modolo, G.; Wilden, A.; Waddell, P. G.; Geist, A.; Panak, P. J.; Wessling, P.; Lewis, F. W., Exploring the Subtle Effect of Aliphatic Ring Size on Minor Actinide-Extraction Properties and Metal Ion Speciation in Bis-1,2,4-Triazine Ligands. Chem. Eur. J. 2020, 26 (2), 428-437.

8. Lewis, F. W.; Harwood, L. M.; Hudson, M. J.; Distler, P.; John, J.; Stamberg, K.; Núñez, A.; Galán, H.; Espartero, A. G., Synthesis and Evaluation of Lipophilic BTBP Ligands for An/Ln Separation in Nuclear Waste Treatment: The Effect of Alkyl Substitution on Extraction Properties and Implications for Ligand Design. Eur. J. Org. Chem. 2012, 2012 (8), 1509-1519.

9. Berthet, J.-C.; Miquel, Y.; Iveson, P. B.; Nierlich, M.; Thuéry, P.; Madic, C.; Ephritikhine, M., The affinity and selectivity of terdentate nitrogen ligands towards trivalent lanthanide and uranium ions viewed from the crystal structures of the $1: 3$ complexes. Dalton Trans. 2002, (16), 3265-3272.

10. Adam, C.; Beele, B. B.; Geist, A.; Müllich, U.; Kaden, P.; Panak, P. J., NMR and TRLFS studies of Ln(iii) and An(iii) C5-BPP complexes. Chem. Sci. 2015, 6 (2), 1548-1561.

11. Adam, C.; Kaden, P.; Beele, B. B.; Müllich, U.; Trumm, S.; Geist, A.; Panak, P. J.; Denecke, M. A., Evidence for covalence in a N-donor complex of americium(III). Dalton Trans. 2013, 42 (39), 14068-74. 12. Adam, C.; Rohde, V.; Müllich, U.; Kaden, P.; Geist, A.; Panak, P. J.; Geckeis, H., Comparative NMR Study of nPrBTP and iPrBTP. Procedia Chemistry 2016, 21, 38-45.

13. Street, K.; Seaborg, G. T., The Separation of Americium and Curium from the Rare Earth Elements. J. Am. Chem. Soc. 1950, 72 (6), 2790-2792.

14. Reichardt, C., Solvatochromic Dyes as Solvent Polarity Indicators. Chem. Rev. 1994, 94 (8), 2319-2358.

15. Abraham, R. J.; Byrne, J. J.; Griffiths, L.; Perez, M., 1 H chemical shifts in NMR: Part 23, the effect of dimethyl sulphoxide versus chloroform solvent on $1 \mathrm{H}$ chemical shifts. Magn. Reson. Chem. 2006, 44 (5), 491-509.

16. Buckingham, A. D.; Schaefer, T.; Schneider, W. G., Solvent Effects in Nuclear Magnetic Resonance. J. Chem. Phys. 1961, 34 (3), 1064-1065.

17. Breault, G. A.; Hunter, C. A.; Mayers, P. C., Influence of Solvent on Aromatic Interactions in Metal Tris-Bipyridine Complexes. J. Am. Chem. Soc. 1998, 120 (14), 3402-3410.

18. Elias, H.; Gumbel, G.; Neitzel, S.; Volz, H., Polarität binärer Lösungsmittelgemische: Bestimmung von ET(30)-Werten und Korrelation mit kinetischen Lösungsmittel-Effekten. Z. Anal. Chem. 1981, 306 (4), 240-244. 
19. Trumm, M.; Adam, C.; Koke, C.; Maiwald, M.; Höfener, S.; Skerencak-Frech, A.; Panak, P. J.; Schimmelpfennig, B., The influence of polarity in binary solvent mixtures on the conformation of bistriazinyl-pyridine in solution. Mol. Phys. 2018, 116 (4), 507-514.

20. Banik, N. L.; Denecke, M. A.; Geist, A.; Modolo, G.; Panak, P. J.; Rothe, J., 2,6-Bis(5,6-dipropyl1,2,4-triazin-3-yl)-pyridine: Structures of An(III) and $\operatorname{Ln}(\mathrm{III})$ 1:3 complexes and selectivity. Inorg. Chem. Commun. 2013, 29, 172-174.

21. Shannon, R. D., Revised effective ionic radii and systematic studies of interatomic distances in halides and chalcogenides. Acta Cryst. 1976, A32, 751-767.

22. David, F., Thermodynamic properties of lanthanide and actinide ions in avueous solution. J. Less-Common Met. 1986, 121, 27-42.

23. Lee, C.; Yang, W.; Parr, R. G., Development of the Colle-Salvetti correlation-energy formula into a functional of the electron density. Phys. Rev. B 1988, 37 (2), 785-789.

24. TURBOMOLE V7.0 2012, a development of University of Karlsruhe and Forschungszentrum Karlsruhe GmbH, 1989-2007, TURBOMOLE GmbH, since 2007; available from http://www.turbomole.com.

25. Küchle, W.; Dolg, M.; Stoll, H.; Preuss, H., Energy-adjusted pseudopotentials for the actinides. Parameter sets and test calculations for thorium and thorium monoxide. J. Chem. Phys. 1994, 100 (10), 7535-7542.

26. Weigend, F.; Ahlrichs, R., Balanced basis sets of split valence, triple zeta valence and quadruple zeta valence quality for $\mathrm{H}$ to Rn: Design and assessment of accuracy. Phys. Chem. Chem. Phys. 2005, 7 (18), 3297-3305.

27. Klamt, A.; Schüürmann, G., COSMO: a new approach to dielectric screening in solvents with explicit expressions for the screening energy and its gradient. J. Chem. Soc., Perkin Trans. 2 1993, (5), 799-805. 